\title{
BIOMARKERS IDENTIFICATION AND THERAPY TARGET IN MACROPHAGE OF ATHEROSCLEROSIS: SYSTEMATIC REVIEW
}

\author{
NENG FISHERI KURNIATI, HUBBI NASHRULLAH MUHAMMAD, GAYUK KALIH PRASESTI* \\ Department of Pharmacology-Clinical Pharmacy, School of Pharmacy, Institut Teknologi Bandung, Bandung, Indonesia. \\ Email: gayukkp@gmail.com
}

Received: 21 November 2020, Revised and Accepted: 06 January 2021

\begin{abstract}
Macrophages are known to play an important role in the initiation and progression of atherosclerosis; however, the molecular signaling pathways in macrophages that are responsible for plaque rupture have not been fully identified. This study aims to identify biomarkers and therapy targets in macrophages in atherosclerotic conditions by systematic review. Research procedure of systematic reviews using the PRISMA protocol. The search engine used in this study is PubMed, with the keywords ([macrophage] AND atherosclerosis) AND (signaling pathway OR signaling pathway), the reference application used is Zotero to screen clinical articles. There were 689 articles identified and 11 clinical articles in inclusion criteria were obtained. The identification resulted in 30 biomarkers associated with macrophages in atherosclerotic conditions. The proposed biomarkers of atherosclerosis are interleukin (IL)-1 $\beta$ and IL-18. The proposed potential therapy targets for atherosclerosis are LOX-1 and schematic images of biomarkers in atherosclerotic plaques.
\end{abstract}

Keywords: Atherosclerosis, Macrophage, Biomarker, Therapy targets, Systematic review

(C) 2021 The Authors. Published by Innovare Academic Sciences Pvt Ltd. This is an open access article under the CC BY license (http://creativecommons.org/ licenses/by/4.0/) DOI: http://dx.doi.org/10.22159/ajpcr.2021v14i3.40336. Journal homepage: https://innovareacademics.in/journals/index.php/ajpcr

\section{INTRODUCTION}

The high incidence of cardiovascular disease is of course directly proportional to the risk factors that influence it. Atherosclerosis is known as a risk factor for cardiovascular disease [1-3]. Atherosclerosis conditions can lead to heart attacks [4] and strokes [5-7] where according to the WHO in 2019, four out of five deaths in the world are related to cardiovascular disease. Cardiovascular disease is the number 1 cause of death globally, an estimated 17.9 million individuals died in 2016 , or $31 \%$ of the total causes of death globally $[8,103]$.

Atherosclerosis is a chronic and progressive inflammatory disease characterized by the buildup of lipids and fibrous plaques in the intima lining of the arterial walls $[9,10]$. Macrophages are known to play an important role in the initiation and progression of atherosclerosis [11-15]. The formation of atherosclerosis is closely related to the function of macrophages in the body. The lesions in atherosclerosis contain a large number of immune cells, especially macrophages [16] and T cells [17-19]. The same thing was stated by Zhang [20] that monocytes and macrophages play an important role in the progression of atherosclerosis, but the mechanism is not fully known.

Macrophages are included in the main cells of the immune system [21-23]. In carrying out its function, macrophages can act as Antigen Presenting Cells (APC) cells and as effector cells $[24,25]$. As APCs, macrophages play a role in capturing antigens to present to lymphocytes while as effector cells macrophages play a role in phagocytosis and the killing of microbes or foreign bodies. Macrophages are blood monocytes that come out into the tissue and differentiate when there is an inflammatory process. Macrophages are found in all connective tissue and organs [104]. According to Dahl [26], macrophages are the center of local inflammatory processes and apoptosis that lead to instability and plaque rupture; however, the molecular signaling pathways in macrophages that are responsible for plaque rupture have not been fully identified.

The early stages of atherosclerosis can occur in adolescence and develop slowly $[27,28]$. Clinical manifestations occur in the elderly and generally have a poor prognosis. Therefore, early detection of atherosclerosis is necessary as an effort to prevent and treat the cardiovascular disease early $[29,30]$. This study aims to identify biomarkers and therapeutic targets in macrophages in atherosclerotic conditions by conducting a systematic review, with the focus of the articles being studied in the form of clinical trial articles.

The role of macrophages in the natural immune system, especially in conditions of atherosclerosis, is of course mediated by a series of molecular signaling pathways that are responsible for these conditions [31-33]. Thus, the importance of identifying biomarkers and therapeutic targets in macrophages in atherosclerotic conditions underlies the reasons for this study. By knowing the role of macrophages, it can be used as a reference in drug development with a targeted system or can be used as blood biomarkers to support the diagnosis of atherosclerosis conditions.

\section{SEARCH STRATEGY AND LITERATURE MANAGEMENT}

This systematic review research uses the PRISMA protocol starting with the search engine determination. The search engine used in this study is PubMed. Determining the search date to limit the addition of articles and determining the keywords used are very important in systematic review research to filter articles that are relevant to the research purpose. Identification was focused on selected clinical articles for further analysis. Initial identification is done by reading through the abstract of each article. The reference application used in this study is Zotero.

The keywords used in the PubMed search box are "macrophage and atherosclerosis" with the search date being set on September 20, 2019. Articles related to the keyword "macrophage and atherosclerosis" are still quite broad, so to narrow the scope and adjust to the research objectives, keywords are added. With the "signaling pathway." Entering the PubMed search box is: ([macrophage] AND atherosclerosis) AND (signaling pathway OR signaling pathway). Then, the articles are grouped by type.

Downloaded journal articles are saved in the Zotero reference application. Then, to filter the scope of the signaling pathway again, in the Zotero search 
box, enter the keyword "signaling pathway" in the all fields, and tags menu with the aim that the signaling pathway in question can be filtered from the entire article content. Initial identification was carried out by abstract screening of each study to differentiate between preclinical and clinical articles. Furthermore, data extraction of clinical articles that meet the criteria is carried out; biomarkers related to macrophages are grouped in atherosclerotic conditions, and further descriptive analysis.

The studies included in this systematic review study were clinical trial articles (original research) contained in PubMed with predetermined keywords and article search times, met inclusion criteria, and were free of exclusion criteria. Eligibility criteria include;

\section{Inclusion criteria}

Articles are original research, published in the PubMed search engine, using English, and clinical research.

\section{Exclusion criteria}

Articles other than original research (review, meta-analysis, and proceedings), preclinical research, and using languages other than English were not used as the subject of articles in this study.

Data on clinical articles that match the inclusion criteria were extracted manually and summarized into a table with data collected: research objectives, objects measured, methods used, patient demographics, and the results or conclusions obtained in each study.

The schematic of the article search process is shown in Fig. 1.

The data were analyzed descriptive and a schematic image of biomarkers was made on plaques containing macrophages in atherosclerotic conditions based on the results of the included clinical studies.

\section{DATA SEARCH RESULTS}

In accordance with the keywords written in the search engine box, the results obtained were 15,390 relevant articles. The 15,390 articles consist of journal articles: 15,113 ; reviews: 3258 ; systematic review: 3 ; clinical trial: 188; clinical study: 202; and 4 meta-analyzes.

The article related to the keyword "macrophage and atherosclerosis" is still quite extensive, so to narrow the scope and adjust to the research objectives, the keyword is added with "signaling pathway." Entering the PubMed search box is: ([macrophage] AND atherosclerosis) AND (signaling pathway OR signaling pathway). The results obtained were 1830 articles consisting of 1425 journal articles and 405 reviews.

1425 article journals are downloaded and stored on the Zotero reference app. Then, to filter the scope of the signaling pathway again, in the Zotero search box, enter the keyword "signaling pathway" in the all fields, and tags menu with the aim that the signaling pathway in question can be filtered from the entire article content. The results obtained were 689 articles with these keywords.

A total of 689 articles were identified based on the type of testing performed, namely, preclinical or clinical. Initial identification was carried out by the abstract screening of each study. The results obtained were 672 preclinical articles and 14 clinical articles. A total of three of the 14 clinical articles obtained were excluded from the study, with the reason that one article used cadaveric/corpse as the subject, and the other two articles did not use a model or sample of patients with atherosclerotic conditions so that a total of 11 clinical articles were subjected to further analysis. The schematic of the article search process and the results are shown in Fig. 2 and the summary table of the research objectives and key conclusions is shown in Table 1.

Based on the flow of the clinical article search process related to biomarkers in macrophages in atherosclerosis conditions, 11 clinical articles that met the criteria were obtained. Furthermore, biomarker identification was carried out for each article. Biomarkers obtained

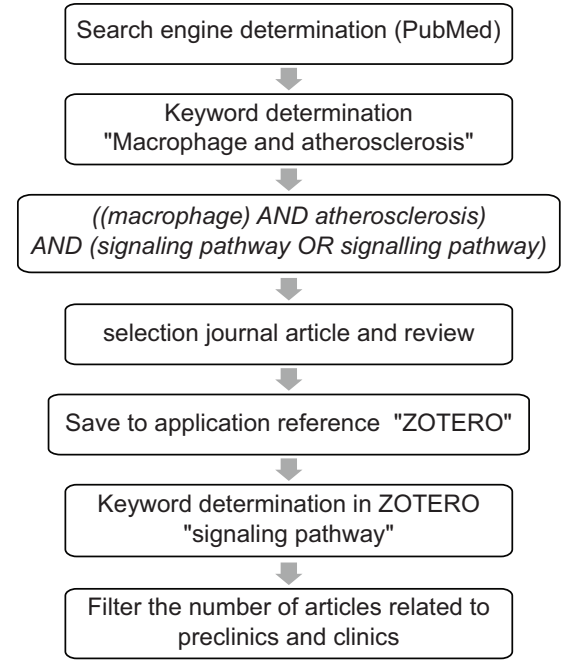

Fig. 1. Schematic of the article search process

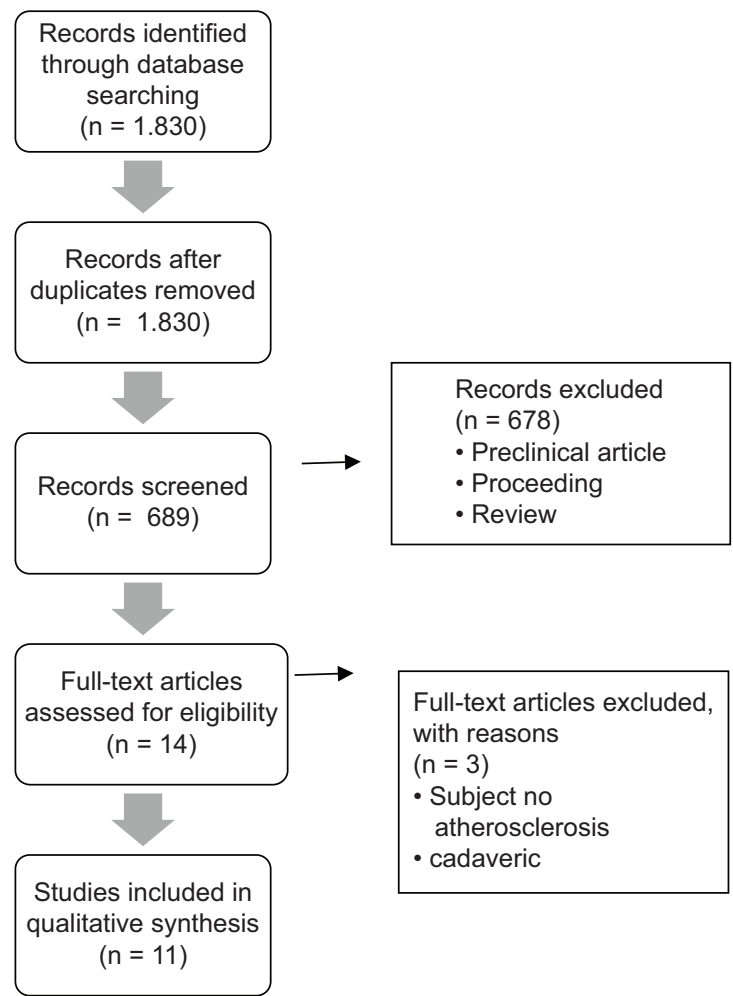

Fig. 2. Article Search Result Schema

based on the identification were 30 biomarkers associated with macrophages in atherosclerotic conditions.

Biomarkers related to inflammatory pathways expressed in plaque were reported by six studies [20,34-38]. Plaque rupture was reported in two studies [39] and [40]. Biomarkers related to metabolic pathways were reported in five studies [20,34,39,41,42]. Types of biomarkers are grouped based on functional gene groups in the body, namely: Lipoproteins and metabolic pathways; adhesion, inflammation, and cell surface antigens; coagulation; gene-linked receptors (extracellular signaling); transport protein; and cell survival. Classification of marker types based on functional class related to the formation process of atherosclerosis along with the reference to the clinical articles included in detail are shown in Table 2 (all markers are upregulated in atherosclerosis except that marked ${ }^{*}$ ). Summary of biomarker values and measurements is shown in Table 3. 
Table 1: Summary of the research objectives and key conclusions

\begin{tabular}{|c|c|c|c|}
\hline Author, Reference & Background/Research purpose & Object & Key conclusion \\
\hline (Shi, 2015) [35] & $\begin{array}{l}\text { Evaluation of the expression of NLRP3 } \\
\text { inflammasome in atherosclerosis } \\
\text { carotid plaque and plaque } \\
\text { susceptibility }\end{array}$ & NLRP3 inflammasome & $\begin{array}{l}\text { - There is an association between the NLRP3 } \\
\text { inflammasome and carotid atherosclerosis. } \\
\text { - NLRP3, ASC, Caspase-1, IL- } 1_{\beta} \text {, IL-18: } \\
\text { Association with plaque vulnerability and } \\
\text { atherogenesis. } \\
\text { - IL- } 1_{\beta} \text {, IL-18 as predictors of atherosclerosis }\end{array}$ \\
\hline (Watanabe, 2017) [37] & $\begin{array}{l}\text { - CAD patients have increased } \\
\text { reactivation of varicella-zoster virus } \\
\text { infection and herpes zoster } \\
\text { - The increase in age causes: } \\
\text { memory loss of CD4 T cells with } \\
\text { the virus, expression of PD-1 } \\
\text { immunoinhibitory receptors. } \\
\text { - Macrophages in CAD patients increase } \\
\text { ROS levels, causing a modification } \\
\text { of the glycolytic enzyme pyruvate } \\
\text { kinase M2 to result in increased IL1 } \beta \\
\text { and IL6 production (leading to cell } \\
\text { disturbance) } \\
\text { - Objective: To see pyruvate control }\end{array}$ & $\begin{array}{l}\text { Ligan immunoinhibitory } \\
\text { (PD-L1) }\end{array}$ & $\begin{array}{l}\text { - Macrophages in CAD suppress T-cell } \\
\text { activation: increase risk of infection by } \\
20-30 \% \\
\text { - Macrophages increase surface expression } \\
\text { of immunoinhibitory ligands (PD-L1) or } \\
\text { program death ligands, due to oversupply } \\
\text { of glycolytic intermediate pyruvate } \\
\text { in mitochondria macrophage CAD } \\
\text { inducing (BMP4/p-SMAD1/5/IRF1) signaling } \\
\text { pathway } \\
\text { - Metabolite-based immunotherapy may be } \\
\text { a potential strategy for restoring adaptive } \\
\text { immunity in CAD patients }\end{array}$ \\
\hline
\end{tabular}

(Zhang, 2018) [20] • Monocytes and macrophages play an important role in the progression of atherosclerosis, but their activities are not fully known

- NAMPT is known to be present as a plaque component, but it is not known whether NAMPT is involved in the regulation of leukocytes in peripheral blood.

- Purpose: To see the effect of NAMPT on the polarization of macrophages related to the NAMPT pathway in atherosclerosis.

(Lee, 2013) [39] • Resident macrophages have an important role in the rupture of atherosclerotic plaques, it is confirmed that there are genes expressed by macrophages.

- Objectives: To see the differences in the characteristics of gene expression in ruptured and stable plaques

(Kang, 2010) [42] • - FOS gene expression, important in the function of monocytes and macrophages. Can be inhibited by statins through disruption of the cholesterol signaling pathway - Purpose: to prove the hypothesis that blood FOS mRNA levels will be sensitive to statins in the treatment of low-density lipoprotein cholesterol levels.

Level NAMPT in ACS patients, IL-1ra, IL-10

- FABP-4 (Fatty acid-binding protein)

- Leptin

FOS Expression in Blood as a low-density lipoprotein-Independent Marker of Statin Treatment FOS: A transcription factor associated with the conversion of monocytes to macrophages FOS: Associated with

atherosclerosis

Localization of FOS in macrophages, smooth muscle cells in plaque has a role in the formation of atherosclerosis

- Statin therapy has an important role Effect of statin on circulating in stabilizing plaque in patients with microRNAome and predicted unstable angina, but the mechanism function regulatory network in has not been much explored.

- Objective: Identification of microRNAs (miRNAs) to mediate the protective effect of statins in patients with unstable angina.
- The expression of NAMPT in PBMC and plasma of patients is higher than in normal patients

- NAMPT/NAD+/Sirt1: up-regulation in ACS patients (due to increased e-NAMPT expression)

- There are significant differences in gene expression produced in stable and ruptured plaques

- There is increased expression of FABP4 and leptin in plaque

- Down-regulation of PPAR/adipocytokine in plaque receiving potent therapy

- Treatment with statins decreases FOS gene expression

- FOS gene expression is sensitive to treatment with statins

- Statins induce multiple miRNA expression in circulating patients with unstable angina, which indicates an important role in the regulation of the signaling pathway for pathogenesis of unstable angina (one of which is NGF signaling) 
Table 1: (Continued)

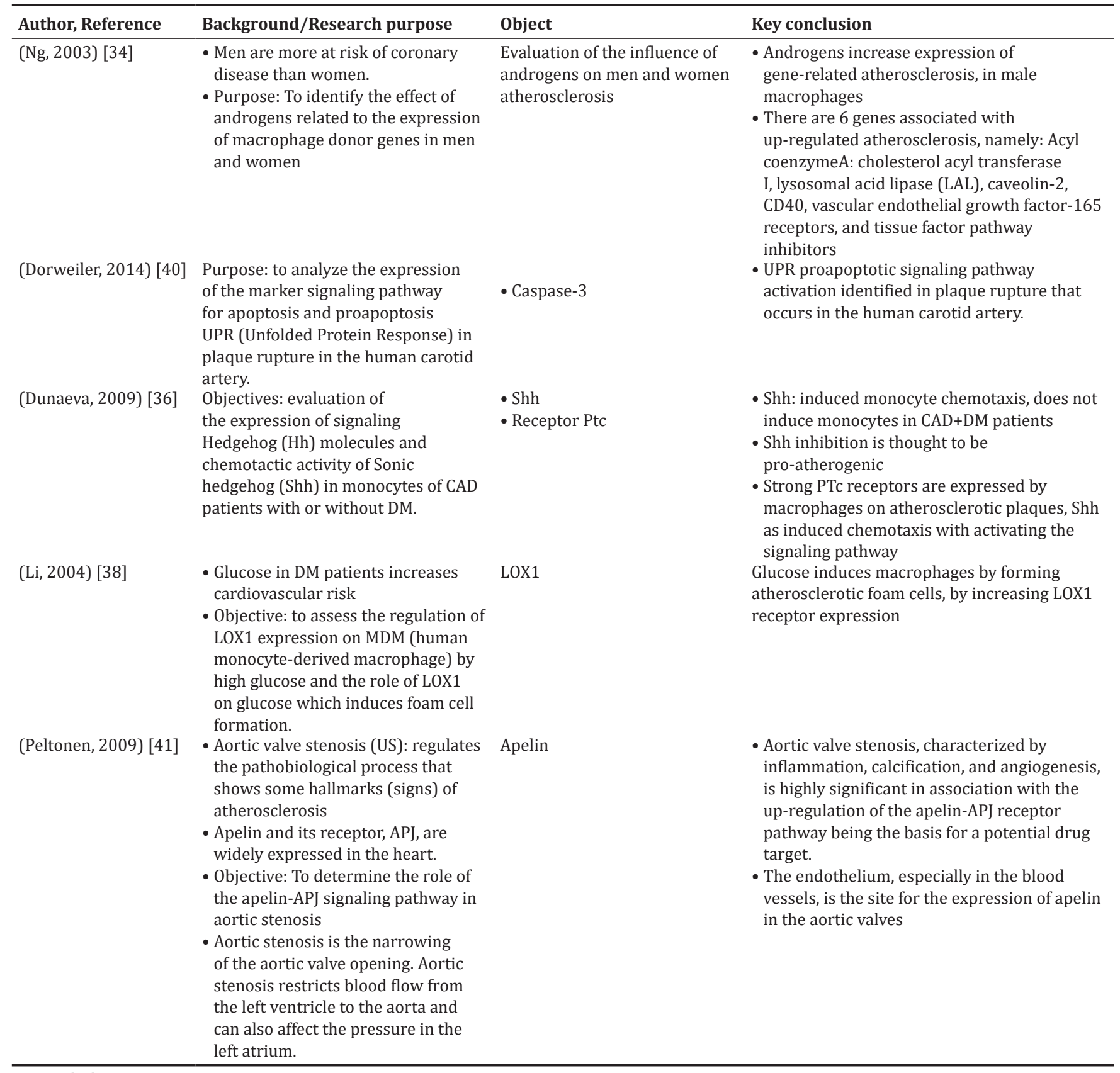

IL: Interleukin

Biomarkers expressed by atherosclerotic plaques included in a systematic review of clinical trials are presented in the form of a schematic image. The induction of chemotaxis is due to an inflammatory response that causes the transfer of monocytes in the blood to the tissues and turns into macrophages. Macrophages which are components of atherosclerotic plaques express several biomarkers, both in ruptured and non-ruptured plaques, are shown in Fig. 3

The results of clinical trial studies indicate a role for macrophages in atherosclerotic conditions. Supported by the expressed biomarkers atherosclerotic plaques containing macrophages were found in this study. The grouping of biomarkers in the study was adjusted to functional gene groups in the body, from the six functional gene groups the most biomarkers were obtained in the adhesion, inflammation, and cell surface antigen groups, namely, 14 biomarkers. This is closely related to atherosclerosis which is basically an inflammatory condition due to the accumulation of low-density lipoprotein cholesterol (particles on the artery walls $[44,45]$.
All studies show mixed results regarding the biomarkers expressed by macrophages, it can be said that none of the studies in this systematic review have the same research results, but still support one another.

Studies [34] have shown that the presence of metabolic pathways (Acyl coenzyme A: cholesterol acyltransferase, Lysosomal acid lipase, and Caveolin-2) and inflammatory pathways (CD-40, TFPI, and VEGF receptor 165) are compatible with atherosclerotic conditions, which are a combination of metabolic processes and inflammation [46-48].

Macrophages are associated with effector function, including secretion of pro-inflammatory cytokines interleukin [IL]-1 $\beta$ and IL-180) [35], lipid uptake, cholesterol transport, and phagocytosis [49]. During the lipid uptake process, macrophages turn into foam cells or foam cells and eventually undergo apoptosis $[50,51]$ which is in line with the study results [40] showing the presence of caspase-3 expression in ruptured plaques. Macrophage apoptosis is the end result of the formation of 
Table 2: Classification of marker types based on functional class

\begin{tabular}{|c|c|c|}
\hline Fungsional Gene & Gene Name/Biomarkers & Reference \\
\hline \multirow[t]{8}{*}{ Lipoprotein and metabolic pathway } & Acyl coenzyme A: cholesterol acyltransferase & [34] \\
\hline & Lysosomal acid lipase & [34] \\
\hline & Caveolin-2 & [34] \\
\hline & NAMPT (Nicotinamide phosphoribosyltransferase) & [20] \\
\hline & Leptin & [39] \\
\hline & Heme oxygenase (decycling) 1 & [39] \\
\hline & Dehydrogenase/reductase (SDR family) member 9 & [39] \\
\hline & FOS & {$[42]$} \\
\hline \multirow[t]{13}{*}{ Adhesi, inflammation and cell surface antigen } & CD 40 & [34] \\
\hline & NLRP3 & [35] \\
\hline & $\begin{array}{l}\text { ASC (apoptosis-associated speck-like protein with a C-terminal } \\
\text { caspase-recruitment domain) }\end{array}$ & [35] \\
\hline & CASPASE - 1 & {$[35]$} \\
\hline & IL- $1_{\beta}$ & [35] \\
\hline & IL- 18 & [35] \\
\hline & IL-10 & {$[20]$} \\
\hline & PD-L1 (Program death ligan -1) & [37] \\
\hline & Proapoptotic caspase adaptor protein & [39] \\
\hline & Fc fragment of IgG, low affinity IIIa/b, receptor (FCGR3AB) & [39] \\
\hline & CD38 antigen (p45) & [39] \\
\hline & Immunoglobulin lambda joining 3 & [39] \\
\hline & Shh* & [36] \\
\hline Coagulation & Tissue factor pathway inhibitor & [34] \\
\hline \multirow[t]{3}{*}{ Gene-linked receptors (extracellular signaling) } & Vascular endothelial cell growth factor 165 receptor & [34] \\
\hline & PTc receptor & [36] \\
\hline & LOX 1 & [38] \\
\hline Protein transport & Fatty acid binding protein 4 (FABP4) & [39] \\
\hline \multirow[t]{2}{*}{ Cell survival } & NGF* & [43] \\
\hline & CASPASE 3 & [40] \\
\hline
\end{tabular}

IL: Interleukin

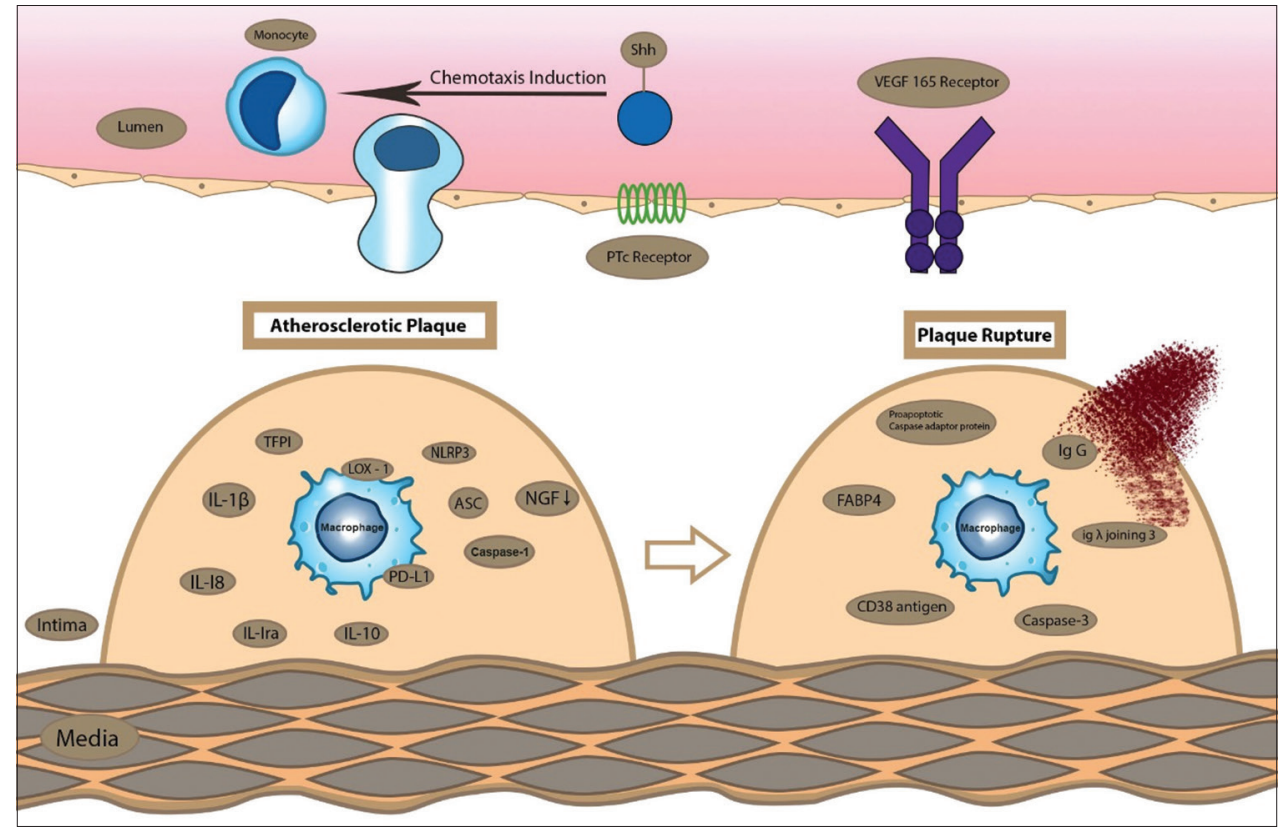

Fig. 3. Biomarkers in atherosclerotic plaques

foam cells as an inflammatory response that is thought to accelerate the process of necrotic nucleation at a later stage [52,53].

At an advanced stage (advanced plaque), macrophages accumulate in the ruptured area. This results in macrophages thought to contribute to the thinning of the fibrous layer and destabilization of atherosclerotic plaque, a mechanism that is thought to be mediated by the secretion of matrix destabilizing matrix metalloproteinases (MMPs) [49,54,55]. However, in this study no information was obtained related to MMPs.

\section{IL-1 $\beta$ AND IL-18 AS PREDICTORS OF ATHEROSCLEROSIS}

Atherogenesis is a biological process that occurs on a molecular scale $[56,57]$ so that molecularly targeted atherosclerosis treatment is still being developed [17,58-64]. Based on this systematic review, biomarkers for the identification of atherosclerosis are proposed, namely IL-1 $\beta$ and IL-18 [35]. Based on statistical tests, it was reported that the plasma levels of IL-1 $\beta$ and IL-18 differed significantly in the conditions of atherosclerotic patients compared with controls. The 


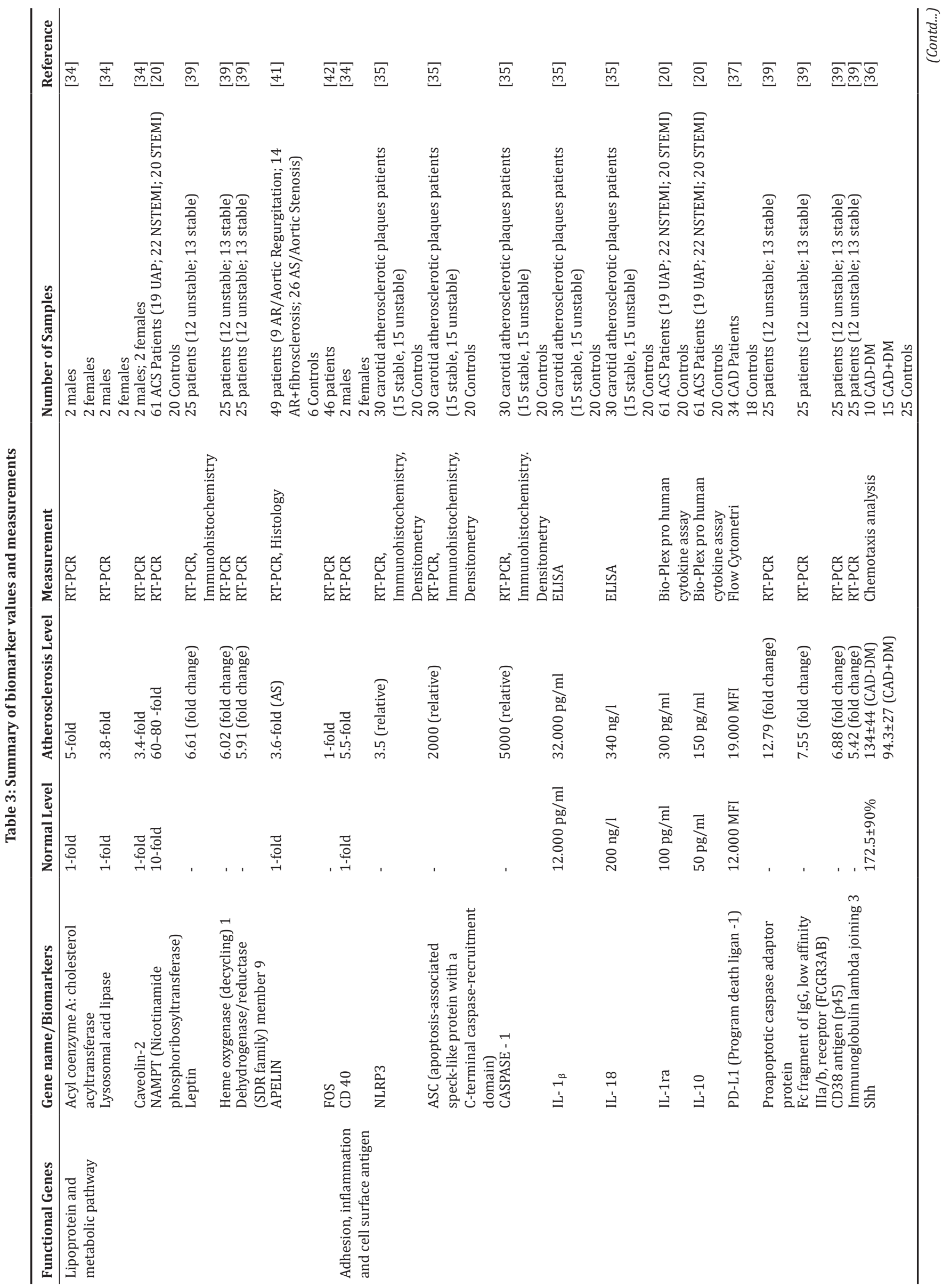




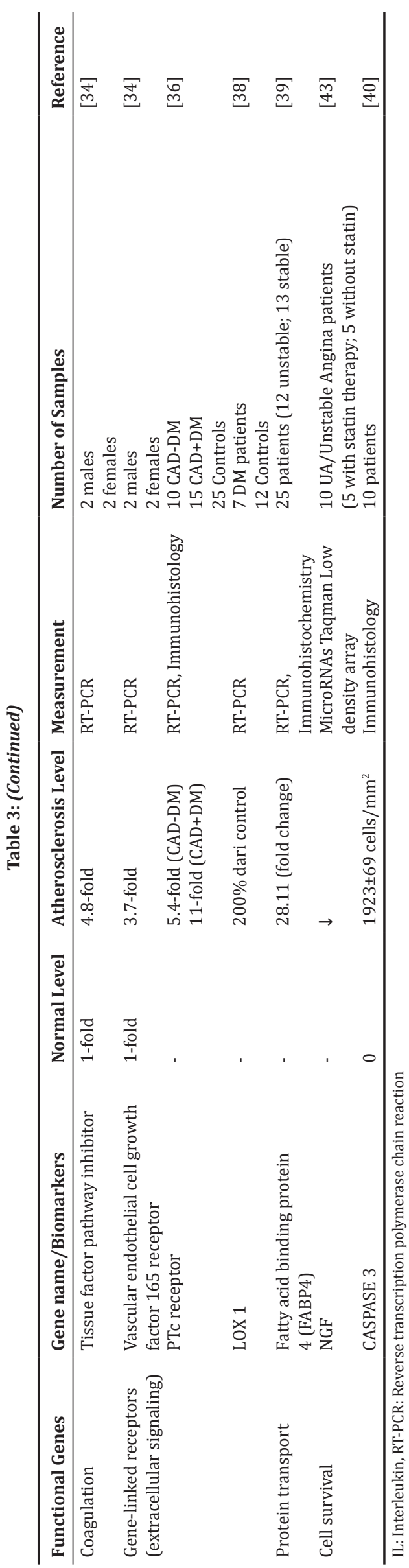

sample used is carotid plaque taken from the patient's surgery so that it can describe the components directly on the plaque. Besides, the results of data extraction from 11 clinical articles showed that only IL- $1 \beta$ and IL-18 were reported to be measured using ELISA (mostly using reverse transcription polymerase chain reaction and immunohistochemistry methods). The plasma IL- $1 \beta$ level is $30,000-35,000 \mathrm{pg} / \mathrm{ml}$ while the plasma IL-18 level is $300-350 \mathrm{ng} / \mathrm{l}$ so that these two biomarkers can be used as predictors of atherosclerosis conditions.

Support data from preclinical research [65] that generated mice lacking both apoE and IL-1 $\beta$. The sizes of atherosclerotic lesions at the aortic sinus in apoE-/-/IL-1 $\beta-/-$ mice at 12 and 24 weeks of age showed a significant decrease of approximately $30 \%$ compared with apoE-/-/ $\mathrm{IL}-1 \beta^{+/+}$mice, and the percentage of the atherosclerotic area to total area of apoE-/-/IL-1 $\beta-/-$ at 24 weeks of age also showed a significant decrease of about $30 \%$ compared with apoE-/-/IL-1 $\beta^{+/+}$. The mRNA levels of vascular cell adhesion molecule (VCAM)-1 and monocyte chemotactic protein- 1 in the apoE-/-/IL-1 $\beta-/-$ aorta were significantly reduced compared with the apoE-/-/IL- $1 \beta^{+/+}$. Furthermore, VCAM1 was also reduced at the protein level in apoE-/-/IL-1 $\beta-/-$ aorta compared with apoE-/-/IL-1 $\beta^{+/+}$. The lack of IL- $1 \beta$ decreases the severity of atherosclerosis in apoE deficient mice, possibly through increased expressions of VCAM- 1 and monocyte chemotactic protein-1 in the aorta.

The other study in vivo [66], XMA052 MG1K, a chimeric murine version of XOMA 052, inhibited the formation of atherosclerotic lesions in the ApoE-/- model at all three doses tested. This effect was comparable to that reported for complete genetic ablation of IL-1 $\beta$ or IL-1R1 on an ApoE-/- background and was associated with decreases in plasma nonHDL/HDL cholesterol ratio and plaque lipid content and macrophage infiltration, demonstrate for the $1^{\text {st }}$ time that an antibody targeting IL$1 \beta$ can inhibit the progression of atherosclerosis in vivo, highlighting the importance of this key cytokine in cardiovascular disease [67-78].

Study of IL-18 in preclinical [79] demonstrated that lack of endogenous IFN- $\gamma$ ablated the effects of IL-18 on atherosclerosis, IL-18 in the atherogenic process[80-93] increases lesion development through enhancement of an inflammatory response involving an IFN- $\gamma-$ dependent mechanism $[94,95]$.

\section{LOX-1 AS A TARGET FOR ATHEROSCLEROSIS THERAPY}

The proposed potential target therapy for the treatment of atherosclerotic conditions is LOX-1 which is a study conducted by Li et al. [38], supported by Xu et al. [96] who stated that LOX-1 is involved in endothelial dysfunction, monocyte adhesion, proliferation, migration, and apoptosis of smooth muscle cells, foam cell formation, platelet activation, and plaque instability; these are all very important in the pathogenesis of atherosclerosis [97-102]. This LOX-1-dependent biological process contributes to plaque instability and the final clinical sequela of life-threatening plaque rupture and tissue ischemia. LOX-1 antagonists are thought to inhibit atherosclerosis by reducing these cellular events.

Over the past decade, many drugs including natural antioxidants, statins, anti-inflammatory agents, antihypertensive, and antihyperglycemic drugs have been shown to inhibit LOX-1 vascular expression and activity. Therefore, LOX-1 is an attractive therapeutic target to be developed in the atherosclerotic treatment in humans [96].

Thus, the complexity of atherosclerotic conditions is supported by 30 biomarkers resulting from 11 clinical trials with macrophages as the main component of atherosclerotic plaque. All test results did not show the same results but were closely related to another.

\section{CONCLUSIONS}

The clinical studies included in this systematic review fit the criteria related to the identification of biomarkers in macrophages in 
atherosclerotic conditions, resulting in a total of 11 clinical trials. The identification resulted in 30 biomarkers which were presented in the form of a schematic image. The proposed biomarkers of atherosclerosis are IL-1 $\beta$ and IL-18, while the proposed potential targets for atherosclerosis therapy are LOX-1.

\section{AUTHORS CONTRIBUTION}

All the authors have contributed to the preparation and editing of this systematic review article.

\section{CONFLICTS OF INTEREST}

The authors declare that they have no conflicts of interest.

\section{AUTHORS FUNDING}

Ministry of Research, Technology and Higher Education of the Republic of Indonesia, 2019

\section{REFERENCES}

1. LaRosa JC. Atherosclerotic risk factors in cardiovascular disease. J Reprod Med 1986;31:906-12.

2. Frostegård J. Immunity, atherosclerosis and cardiovascular disease. BMC Med 2013;11:117.

3. Rafieian-Kopaei M, Setorki M, Doudi M, Baradaran A, Nasri H. Atherosclerosis: Process, indicators, risk factors and new hopes. Int J Prev Med 2014;5:927-46.

4. Lahoz C, Mostaza JM. Atherosclerosis as a systemic disease. Rev Esp Cardiol 2007;60:184-95.

5. Fisher M, Iadecola C, Sacco R. Stroke caused by atherosclerosis of the major intracranial arteries. Circ Res 2017;120:502-13.

6. Gorelick PB, Wong KS, Bae HJ, Pandey DK. Large artery intracranial occlusive disease: A large worldwide burden but a relatively neglected frontier. Stroke 2008;39:2396-9.

7. Hong YM. Atherosclerotic cardiovascular disease beginning in childhood. Korean Circ J 2010;40:1.

8. Khesroh AA, Al-Roumi F, Al-Zakwani I, Attur S, Rashed W, Zubaid M. Gender differences among patients with acute coronary syndrome in the Middle East. Heart Views 2017;18:77-82

9. Davis NE. Atherosclerosis an inflammatory process. J Insur Med 2005;37:72-5

10. Spirig R, Tsui J, Shaw S. The emerging role of TLR and innate immunity in cardiovascular disease. Cardiol Res Pract 2012;2012:181394.

11. Conti P, Shaik-Dasthagirisaeb Y. Atherosclerosis: A chronic inflammatory disease mediated by mast cells. Cent Eur J Immunol 2015;40:380-6.

12. Yamaguchi R, Yamamoto T, Sakamoto A, Ishimaru Y, Narahara S, Sugiuchi $\mathrm{H}$, et al. Roles of myeloperoxidase and GAPDH in interferongamma production of GM-CSF-dependent macrophages. Heliyon 2016;2:e0080.

13. O'neal RM, Still WJ. Pathogenesis of atherosclerosis. Fed Proc 1962;21:12-4

14. Zhong Y, Wang X, Ji Q, Mao X, Tang H, Yi G, et al. CD + LAP + and $\mathrm{CD}_{4}+\mathrm{CD}_{25}+\mathrm{Foxp}_{3}+$ regulatory $\mathrm{T}$ cells induced by nasal oxidized low-density lipoprotein suppress effector $\mathrm{T}$ cells response and attenuate atherosclerosis in ApoE-/-mice. J Clin Immunol 2012;32:1104-17.

15. Gerrity RG, Naito HK. Ultrastructural identification of monocytederived foam cells in fatty streak lesions. Artery 1980;8:208-14.

16. Abdolmaleki F, Hayat SM, Bianconi V, Johnston TP, Sahebkar A. Atherosclerosis and immunity: A perspective. Trends Cardiovasc Med 2019;29:363-71.

17. Tabas I, Lichtman AH. Monocyte-macrophages and $\mathrm{T}$ cells in atherosclerosis. Immunity 2017;47:621-34.

18. Hansson GK. Immune mechanisms in atherosclerosis. Arteriosclerosis Thromb Vasc Biol 2001;21:1876-90.

19. Zhou X, Hansson G. Detection of B cells and proinflammatory cytokines in atherosclerotic plaques of hypercholesterolaemic apolipoprotein $\mathrm{E}$ knockout mice. Scand J Immunol 1999;50:25-30.

20. Zhang C, Zhu R, Wang H, Tao Q, Lin X, Ge S, et al. Nicotinamide phosphate transferase (NAMPT) increases in plasma in patients with acute coronary syndromes, and promotes macrophages to M2 polarization. Int Heart J 2018;59:1116-22.

21. Hirayama D, Iida T, Nakase $H$. The phagocytic function of macrophageenforcing innate immunity and tissue homeostasis. Int $\mathrm{J}$ Mol Sci
2017;19:92

22. Kumar V. Macrophages: The potent immunoregulatory innate immune cells. In: Macrophage Activation Biology and Disease. London: IntechOpen; 2019

23. Marshall JS, Warrington R, Watson W, Kim HL. An introduction to immunology and immunopathology. Allergy Asthma Clin Immunol 2018;14:49.

24. Hume DA. Macrophages as APC and the dendritic cell myth. J Immunol 2008;181:5829-35.

25. Hilhorst M, Shirai T, Berry G, Goronzy JJ, Weyand CM. T cellmacrophage interactions and granuloma formation in vasculitis. Front Immunol 2014;5:432.

26. Dahl TB, Yndestad A, Skjelland M, Øie E, Dahl A, Michelsen A, et al. Increased expression of visfatin in macrophages of human unstable carotid and coronary atherosclerosis: Possible role in inflammation and plaque destabilization. Circulation 2007;115:972-80.

27. Françoso LA, Coates V. Anatomicopathological evidence of the beginning of atherosclerosis in infancy and adolescence. Arq Bras Cardiol 2002;78:137-42.

28. Griffin BA. Lipoprotein atherogenicity: An overview of current mechanisms. Proc Nutr Soc 1999;58:163-9.

29. Duprez DA, Cohn JN. Detection of early cardiovascular disease. In: Willerson JT, Wellens HJ, Cohn JN, Holmes DR, editors. Cardiovascular Medicine. London: Springer; 2007. p. 1615-22.

30. Charo IF, Taub R. Anti-inflammatory therapeutics for the treatment of atherosclerosis. Nat Rev Drug Discov 2011;10:365-76.

31. Moore KJ, Tabas I. The cellular biology of macrophages in atherosclerosis. Cell 2011;145:341-55.

32. Gui T, Shimokado A, Sun Y, Akasaka T, Muragaki Y. Diverse roles of macrophages in atherosclerosis: From inflammatory biology to biomarker discovery. Mediators Inflamm 2012;2012:e693083.

33. Zhai C, Cheng J, Mujahid H, Wang H, Kong J, Yin Y, et al. Selective inhibition of $\mathrm{PI} 3 \mathrm{~K} / \mathrm{Akt} / \mathrm{mTOR}$ signaling pathway regulates autophagy of macrophage and vulnerability of atherosclerotic plaque. PLoS One 2014;9:e90563.

34. Ng MK, Quinn CM, McCrohon JA, Nakhla S, Jessup W, Handelsman DJ, et al. Androgens up-regulate atherosclerosisrelated genes in macrophages from males but not females: Molecular insights into gender differences in atherosclerosis. J Am Coll Cardiol 2003;42:1306-13

35. Shi X, Xie WL, Kong WW, Chen D, Qu P. Expression of the NLRP3 inflammasome in carotid atherosclerosis. J Stroke Cerebrovasc Dis 2015;24:2455-66.

36. Dunaeva M, Voo S, van Oosterhoud C, Waltenberger J. Sonic hedgehog is a potent chemoattractant for human monocytes: Diabetes mellitus inhibits Sonic hedgehog-induced monocyte chemotaxis. Basic Res Cardiol 2010;105:61-71.

37. Watanabe R, Shirai T, Namkoong H, Zhang H, Berry GJ, Wallis BB, et al. Pyruvate controls the checkpoint inhibitor PD-L1 and suppresses T cell immunity. J Clin Invest 2017;127:2725-38.

38. Li L, Sawamura T, Renier G. Glucose enhances human macrophage LOX-1 expression: Role for LOX-1 in glucose-induced macrophage foam cell formation. Circ Res 2004;94:892-901.

39. Lee K, Santibanez-Koref M, Polvikoski T, Birchall D, Mendelow AD, Keavney B. Increased expression of fatty acid binding protein 4 and leptin in resident macrophages characterises atherosclerotic plaque rupture. Atherosclerosis 2013;226:74-81

40. Dorweiler B, Grechowa I, Wallrath A, Vahl CF, Horke S Activation of the proapoptotic unfolded protein response in plaques of the human carotid artery. Eur J Vasc Endovasc Surg 2014;48:248-57.

41. Peltonen T, Näpänkangas J, Vuolteenaho O, Ohtonen P, Soini Y, Juvonen $\mathrm{T}$, et al. Apelin and its receptor APJ in human aortic valve stenosis. J Heart Valve Dis 2009;18:644-52.

42. Kang JG, Sung HJ, Jawed SI, Brenneman CL, Rao YN, Sher S, et al. FOS expression in blood as a LDL-independent marker of statin treatment. Atherosclerosis 2010;212:567-70.

43. Li J, Chen H, Ren J, Song J, Zhang F, Zhang J, et al. Effects of statin on circulating microRNAome and predicted function regulatory network in patients with unstable angina. BMC Med Genomics 2015;8:12.

44. Bäck M, Hansson G. Basic mechanisms of atherosclerosis. In: Chronic Coronary Artery Disease. Amsterdam, Netherlands: Elsevier; 2018. p. $45-54$

45. Libby P, Ridker PM, Hansson GK. Inflammation in atherosclerosis: From pathophysiology to practice. J Am Coll Cardiol 2009;54:2129-38.

46. Barbalho SM, Bechara MD, Quesada K, Gabaldi MR, de Goulart RA, Tofano RJ, et al. Metabolic syndrome, atherosclerosis and inflammation: An inseparable triad? J Vasc Bras 2015;14:319-27. 
47. Galkina E, Ley K. Immune and inflammatory mechanisms of atherosclerosis. Annu Rev Immunol 2009;27:165-97.

48. Paoletti R, Bolego C, Poli A, Cignarella A. Metabolic syndrome, inflammation and atherosclerosis. Vasc Health Risk Manag 2006;2:145-52.

49. Wolf D, Stachon P, Bode C, Zirlik A. Inflammatory mechanisms in atherosclerosis. Hamostaseologie 2014;34:63-71.

50. Moore K, Sheedy F, Fisher E. Macrophages in atherosclerosis: A dynamic balance. Nat Rev Immunol 2013;13:709-21.

51. Turner C, Devitt A, Parker K, MacFarlane M, Giuliano M, Cohen G, et al. Macrophage-mediated clearance of cells undergoing caspase-3independent death. Cell Death Differ 2003;10:302-12.

52. Gonzalez L, Trigatti BL. Macrophage apoptosis and necrotic core development in atherosclerosis: A rapidly advancing field with clinical relevance to imaging and therapy. Can J Cardiol 2017;33:303-12.

53. Martinet W, Verheye S, De Meyer GR. Selective Depletion of macrophages in atherosclerotic plaques via macrophage-specific initiation of cell death. Trends Cardiovasc Med 2007;17:69-75.

54. Razavian M, Tavakoli S, Zhang J, Nie L, Dobrucki LW, Sinusas AJ, et al. Atherosclerosis plaque heterogeneity and response to therapy detected by in vivo molecular imaging of matrix metalloproteinase activation. J Nucl Med 2011;52:1795-802.

55. Wågsäter D, Zhu C, Björkegren J, Skogsberg J, Eriksson P. MMP-2 and MMP-9 are prominent matrix metalloproteinases during atherosclerosis development in the Ldlr(-/-)Apob(100/100) mouse. Int J Mol Med 2011;28:247-53.

56. Mannarino E, Pirro M. Molecular biology of atherosclerosis. Clin Cases Miner Bone Metab 2008;5:57-62.

57. Hopkins PN. Molecular biology of atherosclerosis. Physiol Rev 2013;93:1317-542.

58. Alfarisi HA, Mohamed ZB, Ibrahim MB. Basic pathogenic mechanisms of atherosclerosis. Egypt J Basic Appl Sci 2020;7:116-25.

59. Zhang X, Li J, Qin JJ, Cheng WL, Zhu X, Gong FH, et al. Oncostatin $M$ receptor $\beta$ deficiency attenuates atherogenesis by inhibiting JAK2/ STAT3 signaling in macrophages. J Lipid Res 2017;58:895-906.

60. Zhang J, Zu Y, Dhanasekara CS, Li J, Wu D, Fan Z, et al. Detection and treatment of atherosclerosis using nanoparticles: Detection and treatment of atherosclerosis using nanoparticles. WIREs Nanomed Nanobiotechnol 2017;9:e1412.

61. Jamkhande PG, Chandak PG, Dhawale SC, Barde SR, Tidke PS, Sakhare RS. Therapeutic approaches to drug targets in atherosclerosis. Saudi Pharm J 2014;22:179-90.

62. Rashid I, Maghzal GJ, Chen YC, Cheng D, Talib J, Newington D, et al. Myeloperoxidase is a potential molecular imaging and therapeutic target for the identification and stabilization of high-risk atherosclerotic plaque. Eur Heart J 2018;39:3301-10.

63. Adameova A, Xu YJ, Duhamel TA, Tappia PS, Shan L, Dhalla NS. Antiatherosclerotic molecules targeting oxidative stress and inflammation. Curr Pharm Des 2009; 15:3094-107.

64. Wickline SA, Neubauer AM, Winter PM, Caruthers SD, Lanza GM. Molecular imaging and therapy of atherosclerosis with targeted nanoparticles. J Magn Reson Imaging 2007;25:667-80.

65. Kirii H, Niwa T, Yamada Y, Wada H, Saito K, Iwakura Y, et al. Lack of interleukin-1 $\beta$ decreases the severity of atherosclerosis in apoEdeficient mice. Arterioscler Thromb Vasc Biol 2003;23:656-60.

66. Bhaskar V, Yin J, Mirza AM, Phan D, Vanegas S, Issafras H, et al. Monoclonal antibodies targeting IL-1 beta reduce biomarkers of atherosclerosis in vitro and inhibit atherosclerotic plaque formation in apolipoprotein E-deficient mice. Atherosclerosis 2011;216:313-20.

67. Viana-Huete V, Fuster JJ. Potential therapeutic value of interleukin $1 \mathrm{~b}$-targeted strategies in atherosclerotic cardiovascular disease. Rev Esp Cardiol 2019;72:760-6.

68. Sterpetti AV. Inflammatory cytokines and atherosclerotic plaque progression. therapeutic implications. Curr Atheroscler Rep 2020;22:75.

69. Mai W, Liao Y. Targeting IL-1 $\beta$ in the treatment of atherosclerosis. Front Immunol 2020;11:589654.

70. Khan R, Rheaume E, Tardif JC. Examining the role of and treatment directed at IL-1 $\beta$ in atherosclerosis. Curr Atheroscler Rep 2018;20:53.

71. Moriya J. Critical roles of inflammation in atherosclerosis. J Cardiol $2019 ; 73: 22-7$

72. Chamberlain J, Evans D, King A, Dewberry R, Dower S, Crossman D, et al. Interleukin-1beta and signaling of interleukin-1 in vascular wall and circulating cells modulates the extent of neointima formation in mice. Am J Pathol 2006;168:1396-403.

73. Kamari Y, Werman-Venkert R, Shaish A, Werman A, Harari A, Gonen A, et al. Differential role and tissue specificity of interleukin-1alpha gene expression in atherogenesis and lipid metabolism. Atherosclerosis $2007 ; 195: 31-8$
74. Englesbe MJ, Deou J, Bourns BD, Clowes AW, Daum G. Interleukin-1 $\beta$ inhibits PDGF-BB-induced migration by cooperating with PDGF-BB to induce cyclooxygenase-2 expression in baboon aortic smooth muscle cells. J Vasc Surg 2004;39:1091-6.

75. Wang X, Feuerstein GZ, Gu JL, Lysko PG, Yue TL. Interleukin-1 beta induces expression of adhesion molecules in human vascular smooth muscle cells and enhances adhesion of leukocytes to smooth muscle cells. Atherosclerosis 1995;115:89-98.

76. Galea J, Armstrong J, Gadsdon P, Holden H, Francis SE, Holt CM. Interleukin-1 beta in coronary arteries of patients with ischemic heart disease. Arterioscler Thromb Vasc Biol 1996;16:1000-6.

77. Roell MK, Issafras H, Bauer RJ, Michelson KS, Mendoza N, Vanegas SI, et al. Kinetic approach to pathway attenuation using XOMA 052, a regulatory therapeutic antibody that modulates interleukin-1beta activity. J Biol Chem 2010;285:20607-14.

78. Owyang AM, Issafras H, Corbin J, Ahluwalia K, Larsen P, Pongo E, et al. XOMA 052, a potent, high-affinity monoclonal antibody for the treatment of IL-1 $\beta$-mediated diseases. MAbs 2011;3:49-60.

79. Whitman SC, Ravisankar P, Daugherty A. Interleukin-18 enhances atherosclerosis in apolipoprotein E-/-mice through release of interferon- $\gamma$. Circ Res 2002;90:E34-8.

80. Bhat OM, Kumar PU, Giridharan NV, Kaul D, Kumar MJ, Dhawan V. Interleukin-18-induced atherosclerosis involves CD36 and NF-кB crosstalk in Apo E-/-mice. J Cardiol 2015;66:28-35.

81. Yamaoka-Tojo M, Tojo T, Wakaume K, Kameda R, Nemoto S, Takahira N, et al. Circulating interleukin-18: A specific biomarker for atherosclerosisprone patients with metabolic syndrome. Nutr Metab 2011;8:3.

82. Wang J, Sun C, Gerdes N, Liu C, Liao M, Liu J, et al. Interleukin 18 function in atherosclerosis is mediated by the interleukin 18 receptor and the Na-Cl co-transporter. Nat Med 2015;21:820-6.

83. Badimon L. Interleukin-18: A potent pro-inflammatory cytokine in atherosclerosis: Expert's perspective. Cardiovasc Res 2012;96:172-5.

84. Jefferis BJ, Papacosta O, Owen CG, Wannamethee SG, Humphries SE, Woodward M, et al. Interleukin 18 and coronary heart disease: Prospective study and systematic review. Atherosclerosis 2011;217:227-33.

85. Elhage R, Jawien J, Rudling M, Ljunggren HG, Takeda K, Akira S, et al. Reduced atherosclerosis in interleukin-18 deficient apolipoprotein E-knockout mice. Cardiovasc Res 2003;59:234-40.

86. Tang X. Analysis of interleukin-17 and interleukin-18 levels in animal models of atherosclerosis. Exp Ther Med 2019;18:517-22.

87. Munckhof IV, ter Horst R, Schraa K, Stienstra R, de Graaf J, Riksen N, et al. Il-18 Binding protein: A novel biomarker in obesity-related atherosclerosis that modulates lipoprotein metabolism. Atherosclerosis 2019;287:e75.

88. Formanowicz D, Gutowska K, Formanowicz P. Theoretical studies on the engagement of interleukin 18 in the immuno-inflammatory processes underlying atherosclerosis. Int J Mol Sci 2018;19:3476.

89. Nakamura A, Shikata K, Hiramatsu M, Nakatou T, Kitamura T, Wada J, et al. Serum interleukin-18 levels are associated with nephropathy and atherosclerosis in Japanese patients with Type 2 diabetes. Diabetes Care 2005;28:2890-5.

90. Hernesniemi JA, Heikkilä A, Raitakari OT, Kähönen M, Juonala M, Hutri-Kähönen $\mathrm{N}$, et al. Interleukin-18 gene polymorphism and markers of subclinical atherosclerosis. The cardiovascular risk in young finns study. Ann Med 2010;42:223-30

91. Sadeghi M, Gheraati M, Soleimani A, Amirpour A, Taheri M, Yazdekhasti S, et al. Serum interleukin-18 and extent of coronary artery disease in unstable angina. ARYA Atheroscler 2018;14:122-7.

92. Scherr C, de Albuquerque DC, Pozzan R, Ataide K, Ludmila T, Blanco F, et al. Role of interleukin-18 and the thrombus precursor protein in coronary artery disease. Arq Bras Cardiol 2020;114:692-8.

93. Autieri MV. Pro-and anti-inflammatory cytokine networks in atherosclerosis. ISRN Vasc Med 2012;2012:e987629.

94. Ranjbaran H, Sokol SI, Gallo A, Eid RE, Iakimov AO, D’Alessio A, et al. An inflammatory pathway of IFN- $\gamma$ production in coronary atherosclerosis. J Immunol 2007; 178:592-604.

95. Harvey E, Ramji D. Interferon- $\gamma$ and atherosclerosis: Pro-or antiatherogenic? Cardiovasc Res 2005;67:11-20.

96. Xu S, Liu Z, Huang Y, Le K, Tang F, Huang H, et al. Tanshinone II-A inhibits oxidized LDL-induced LOX-1 expression in macrophages by reducing intracellular superoxide radical generation and NF- $\mathrm{KB}$ activation. Transl Res 2012;160:114-24.

97. Jin P, Cong S. LOX-1 and atherosclerotic-related diseases. Clin Chim Acta 2019;491:24-9

98. Pothineni NV, Karathanasis SK, Ding Z, Arulandu A, Varughese KI, Mehta JL. LOX-1 in atherosclerosis and myocardial ischemia: Biology, genetics, and modulation. J Am Coll Cardiol 2017;69:2759-68.

99. Henning M. LOX-1 and atherosclerosis. Circ Res 2007;100:1534-6. 
100. Tian K, Ogura S, Little PJ, Xu SW, Sawamura T. Targeting LOX-1 in atherosclerosis and vasculopathy: Current knowledge and future perspectives. Ann N Y Acad Sci 2019;1443:34-53.

101. Pirillo A, Norata GD, Catapano AL. LOX-1, OxLDL, and atherosclerosis. Mediators Inflamm 2013;2013:e152786.

102. Mehta JL, Chen J, Hermonat PL, Romeo F, Novelli G. Lectin-like, oxidized low-density lipoprotein receptor-1 (LOX-1): A critical player in the development of atherosclerosis and related disorders.
Cardiovasc Res 2006;69:36-45.

103. World Health Organization. Data About Cardiovascular Diseases in the World. Geneva: World Health Organization; 2019. Available from: https://www.who.int/en/news-room/fact-sheets/detail/cardiovasculardiseases-(cvds). [Last accessed on 2019 Dec 16].

104. Abbas AK. Basic Immunology: Functions and Disorders of the Immune System. $5^{\text {th }}$ ed. Singapore: Elsevier; 2016. 